\title{
EscolarizaÇão INClusiva de ALunos com Autismo na Rede Municipal de ENSINO DE BELO Horizonte ${ }^{1}$ \\ InCLusive schooling of STUdents With autism in Municipal EdUCATION of BeLo HORIZONTE
}

\author{
Camila Graciella Santos GOMES ${ }^{2}$ \\ Enicéia Gonçalves MENDES ${ }^{3}$
}

RESUMO: o direito a matrícula de alunos com necessidades educacionais especiais em escolas regulares no Brasil é garantido por lei desde a Constituição de 1988. Os dados do Censo Escolar do Ministério da Educação indicam aumento no número de matrícula desses alunos no país ao longo dos anos, especialmente em escolas da rede municipal de ensino. Entre os alunos enquadrados na definição de "necessidades especiais" encontram-se aqueles com autismo, caracterizados por apresentarem alterações na interação social, na comunicação e pela presença de padrões estereotipados de comportamento. A prefeitura de Belo Horizonte - MG vem desenvolvendo ações com o intuito de favorecer o acesso de estudantes com autismo a escolas regulares do município, porém dados sobre o andamento deste processo são escassos. O objetivo desse estudo consistiu em caracterizar os alunos com autismo matriculados em escolas municipais regulares de Belo Horizonte, assim como descrever a maneira pela qual essa escolarização vem ocorrendo nas escolas comuns, a partir da perspectiva de seus professores. Participaram do estudo trinta e três professores da rede regular de ensino do município que tinham contato direto e diário com alunos com autismo. Foram utilizados um questionário semi-estruturado e a escala CARS (Childhood Autism Rating Scale). Os resultados indicaram que as estratégias utilizadas pela prefeitura parecem favorecer a freqüência dos alunos com autismo, porém há evidências de que eles participam pouco das atividades da escola, a interação com os colegas é escassa e a aprendizagem de conteúdos pedagógicos é limitada.

PALAVRAS-CHAVE: educação especial; autismo; inclusão educacional; diagnóstico; características do educando.

\begin{abstract}
The right to enroll students with special needs in regular schools in Brazil is guaranteed by law since the 1988 Constitution. Ministry of Education school census data indicates that the number of students with special needs enrolled in regular schools in the country has increased over the years, especially in the municipal system of education. Among the students regarded as having "special needs" are those with autism, who show impairment in social interaction, communication and stereotypical behavior patterns. The city of Belo Horizonte - MG has been taking action in order to improve access for students with autism in regular schools in the city, but data of the progress of this process is scarce. The purpose of this research was to characterize the students with autism enrolled in regular public schools in Belo Horizonte, as well as describe the way in which this schooling is occurring in regular schools, from the perspective of the teachers. Thirtythree teachers who had direct and daily contact with students with autism in regular schools in the city participated in this research. A semi-structured questionnaire and the Childhood Autism Rating Scale (CARS) were used. The results indicated that the strategies used by the city seem to enable the presence of the students with autism in the schools, but there is evidence that their participation in school activities is restricted, the interactions with their peers is scarce, and the content learned from the school curriculum is limited.
\end{abstract}

KEYWORDS: Special Education; Autism; Educational Inclusion; Diagnosis; Student Characteristics.

\footnotetext{
${ }^{1}$ Agradecemos à Dra. Maria Stella C.A. Gil, à Dra. Tânia M.S. de Rose, à Rafiza Drumond C. Lobato, a Odilon M. da Mata, ao Núcleo de Inclusão Escolar de Belo Horizonte e às escolas e professores participantes, pelas colaborações durante a realização deste estudo.

${ }^{2}$ Doutoranda do Programa de Pós-Graduação em Educação Especial - Universidade Federal de São Carlos (UFSCar) Bolsista de doutorado do CNPQ - Brasil - camilagsg@uol.com.br

${ }^{3}$ Doutora em Psicologia. Professora adjunta do Departamento de Psicologia da Universidade Federal de São Carlos (UFSCar) - Programa de Pós-Graduação em Educação Especial - egmendes@ ufscar.br
} 


\section{INTRODUÇÃo}

O direito a matrícula de alunos com necessidades educacionais especiais em escolas regulares no Brasil é garantido por lei desde a Constituição de 1988 a qual estabeleceu: o direito à escolarização de toda e qualquer pessoa, a igualdade de condições para o acesso e para a permanência na escola e a garantia de "atendimento educacional especializado aos portadores de deficiência, preferencialmente na rede regular de ensino" (BRASIL, 1988). A Lei de Diretrizes e Bases da Educação Nacional (9.394/96) de 1996 reafirmou a obrigatoriedade do atendimento educacional especializado e gratuito aos estudantes com necessidades especiais, preferencialmente na rede regular de ensino, e foi a partir daí que as práticas educacionais inclusivas ganharam força no país (BRASIL, 1996).

Dados do Censo Escolar do Ministério da Educação e Cultura (MEC/INEP) destacaram o aumento no número de matrículas de alunos com necessidades educacionais especiais de ensino em $640 \%$ nas escolas regulares contra $28 \%$ nas escolas e classes especiais, entre os anos de 1998 e 2006. Além disso, o Censo apontou o crescimento de $146 \%$ de matriculas de alunos especiais em escolas públicas regulares e $64 \%$ em escolas privadas regulares (BRASIL, 2007).

Entre os alunos considerados na definição oficial de "necessidades educacionais especiais", encontram-se pessoas com autismo (BRASIL, 2008). O conceito de autismo e os critérios utilizados para o diagnóstico sofreram mudanças ao longo dos anos e a definição atual mais utilizada é a da quarta versão revisada do Manual Diagnóstico e Estatístico de Transtornos Mentais; DSM-IV-TR (ASSOCIAÇÃO AMERICANA DE PSIQUIATRIA, 2002), que classifica o autismo na categoria de Transtornos Globais do Desenvolvimento e que, por sua vez, engloba as seguintes condições: Transtorno autista, Transtorno de Rett, Transtorno desintegrativo da infância, Transtorno de Asperger e Transtorno global do desenvolvimento sem outra especificação (autismo atípico).

Todos os transtornos globais são caracterizados por alterações qualitativas na interação social recíproca, na comunicação e pela presença de um padrão restrito e repetitivo de comportamento, com início dos sintomas, no geral, antes dos três anos de idade (ASSOCIAÇÃO AMERICANA DE PSIQUIATRIA, 2002). Segundo Klin (2006), os transtornos globais refletem uma variedade de apresentações clínicas de uma pessoa afetada para outra, tanto em relação ao perfil da sintomatologia quanto ao grau de acometimento, e incluem condições que estão invariavelmente relacionadas à deficiência mental (síndrome de Rett e transtorno desintegrativo da infância), condições que podem ou não estar relacionadas à deficiência mental (transtorno autista e autismo atípico) e condição associada à inteligência normal (síndrome de Asperger).

Assim, quando se fala em "autismo" fala-se na verdade em um contínuo ou espectro de distúrbios (WING, 1996), que inclui todos os transtornos globais exceto transtorno de Rett. Segundo Blaxill (2004), a partir da década de 1990, observa-se na literatura a tendência dos pesquisadores a adotar o termo Transtornos 
do Espectro Autístico para a definição de autismo, especialmente nos estudos sobre a prevalência do transtorno. Klin (2006) salienta que esse termo tenta interconectar condições distintas que apresentam sintomatologia em comum.

Em relação ao número de casos de autismo na população, Filipek e colaboradores (1999) destacam que não se trata de um transtorno raro: a prevalência na população pediátrica é superior ao câncer, a diabetes, a espinha bífida e a síndrome de Down. Os números são bastante controversos e, apesar do DSM-IVTR (ASSOCIAÇÃO AMERICANA DE PSIQUIATRIA, 2002) considerar a estimativa de 15 casos em cada 10.000 indivíduos, ou um caso de autismo em aproximadamente 666 pessoas, outras fontes estimam valores diferentes. Baird e colaboradores (2006), por exemplo, indicaram 116,1 casos de Transtornos do Espectro Autístico em cada 10.000 indivíduos, ou um caso em cada 86 pessoas, o que, segundo esses pesquisadores, resulta na proporção estimada de $1 \%$ da população infantil apresentando algum tipo de Transtorno do Espectro Autístico.

Apesar dos estudos sobre a prevalência do autismo indicarem que o número de pessoas afetadas pelo transtorno na população é superior ao da Síndrome de Down, que é cerca de 5,9 casos em cada 10.000 pessoas, ou um caso em aproximadamente 1.695 pessoas (MANTRY et al., 2008), os dados do censo escolar do MEC/INEP de 2007 indicaram que o número de matrículas de alunos com autismo em escolas (especiais ou regulares) representa 1,5\% de toda a população de estudantes com necessidades educacionais especiais matriculados em escolas no Brasil, enquanto que a porcentagem de alunos com Síndrome de Down é de 5,4\% (BRASIL, 2007).

Esses dados sugerem duas hipóteses: ou poucos alunos com autismo estão matriculados em escolas, sejam elas regulares ou especiais, ou muitos dos alunos com autismo foram enquadrados em outras categorias, como na de "condutas típicas" que representa $12,4 \%$ das matrículas, ou mesmo na de "deficiência mental" que representa $43,4 \%$. As duas hipóteses são bastante viáveis considerando que a complexidade da condição do autismo pode ser um fator que dificulte a entrada de pessoas com esse diagnóstico em escolas. Por outro lado, a falta de diagnóstico diferencial mais preciso pode levar ao enquadramento dessas pessoas na categoria de "condutas típicas", devido à presença de comportamentos típicos no autismo, ou ainda na categoria de "deficiência mental", em função da alta porcentagem de deficiência intelectual associada ao autismo.

Muitos estudos têm enfocado a escolarização inclusiva de alunos especiais (escolarização em escolas comuns, regulares), porém foram encontrados poucos trabalhos sobre o assunto envolvendo especificamente alunos com autismo (ALVES, 2005; BRAGA, 2002; KERN, 2005; LAGO, 2007; LIRA, 2004; MARTINS, 2007; MELO, 2004; RUBLESCKI, 2004; SERRA, 2004; SERRA, 2008).

Alguns estudos descreveram aspectos pontuais de professores de alunos com autismo de escolas comuns como: a concepção deles a respeito da escolarização inclusiva de seus alunos com autismo (LIRA, 2004; MARTINS, 2007); as 
representações sociais dos professores a cerca da inclusão escolar (ALVES, 2005); a descrição de variáveis que influenciavam na escolha de estratégias de ensino (LAGO, 2007); e a interação entre o professor e o aluno com autismo (BRAGA, 2002).

Outros trabalhos descreveram por meio de estudos de caso a escolarização inclusiva de alunos com autismo (KERN, 2005; SERRA, 2004; RUBLESCKI, 2004). Kern (2005) investigou um processo considerado bem-sucedido de escolarização inclusiva de um aluno com autismo, por meio da sistematização da história de vida do sujeito. Neste caso, o percurso escolar envolveu o ingresso e uma estadia anterior do aluno na escola especial com a posterior transferência para uma escola regular. Foram analisados e discutidos os aspectos culturais, sociais e históricos envolvidos no processo de escolarização desse aluno. Serra (2004) descreveu a escolarização inclusiva de uma criança com autismo e verificou benefícios desse tipo de educação no desenvolvimento da criança analisada. Rublescki (2004) investigou o processo educacional de quatro crianças com autismo matriculadas no ensino regular da região metropolitana de Porto Alegre, através de entrevistas com os profissionais envolvidos na escolarização dos alunos (professores, educadores especiais, assessores e gestores), visitas às escolas e participação em reuniões destinadas à assessoria e à formação de professores. Os resultados indicaram que a escola regular promoveu o desenvolvimento de alguns aspectos dos alunos avaliados e, além disso, foram constatadas semelhanças entre o ensino regular e o ensino especial, em decorrência dos recursos de apoio utilizados com esses alunos.

Melo (2004) e Serra (2008) analisaram comunidades escolares que apresentavam alunos com autismo, discutiram a legislação e as políticas públicas. No trabalho de Melo (2004) foi realizado um estudo etnográfico que mapeou as interações entre os membros da comunidade escolar de um aluno com autismo (professoras, merendeiras, diretora, orientadora escolar, colegas de classe e familiares), o que possibilitou a descrição minuciosa do contexto escolar e a análise das interações entre os participantes. A partir dos dados levantados a pesquisadora discutiu os conceitos de inclusão, exclusão e as políticas públicas, sugerindo alternativas e possíveis soluções para problemas encontrados no atendimento educacional a pessoas com autismo. Serra (2008) discutiu o processo de inclusão de alunos com autismo nas classes regulares de escolas públicas de duas prefeituras da baixada fluminense do Estado do Rio de Janeiro. Realizou-se uma análise da legislação brasileira confrontando-a com a realidade das escolas, a partir de dados levantados por meio de entrevistas realizadas com professores, familiares e colegas de sala de alunos com autismo.

Em resumo, a tradição de pesquisas sobre autismo parece envolver metodologias de estudos de casos com alguns poucos participantes, que embora retratem a situação atual não permitem avaliar adequadamente políticas de sistemas educacionais em maior escala para a escolarização de crianças e jovens com autismo.

Seguindo a tendência de municipalização na educação de alunos com necessidades especiais e atendendo ao direito legal a matrícula preferencialmente 
em escolas regulares, a prefeitura de Belo Horizonte vem desenvolvendo ações para favorecer o acesso de alunos com necessidades educacionais especiais nas escolas comuns da rede municipal. Segundo dados do município, o número de matrículas de alunos com necessidades educacionais especiais em escolas regulares passou de 784 em 2001 para 1.636 em 2006, o que representou um aumento de $48 \%$ (BELO HORIZONTE, 2007). No ano de 2007, segundo dados apresentados no sítio do município, foram atendidos na Educação Infantil (zero a cinco anos) e no $1^{\circ}$ ciclo (seis a nove anos) 1.878 estudantes com necessidades educacionais especiais. Desse total, 506 eram considerados estudantes com deficiência mental, 426 com deficiência física, 331 com condutas típicas, 32 com autismo, 264 com surdez, 157 com cegueira e 194 com deficiências múltiplas (BELO HORIZONTE, 2008).

Assim, os dados oficiais de 2007 indicavam que 32 crianças com diagnóstico de autismo estavam matriculadas em escolas comuns do município, porém não havia uma descrição detalhadas sobre esses alunos. Faltavam informações sobre as características básicas (ex. gênero, idade, presença ou ausência de fala); a sistemática da matrícula desses alunos (distribuição de alunos por séries / ciclos, correspondência entre a série/ciclo e a idade cronológica dos alunos); o suporte fornecido aos alunos e aos professores; a frequência, a permanência e a monitoração dos efeitos dessa escolarização na aprendizagem de conteúdos pedagógicos e no desenvolvimento dessas crianças. Tais informações poderiam favorecer não só a compreensão do processo de educação de alunos com autismo nas escolas regulares da prefeitura de Belo Horizonte, como também da escolarização inclusiva de alunos com autismo de forma geral.

Considerando que intervenções educacionais têm se mostrado fundamentais no tratamento do autismo (AIELLO, 2002), ambientes escolares, que são genuinamente espaços de intervenção educacional, tornam-se um importante meio para favorecer o desenvolvimento de crianças com esse diagnóstico. Considerando também que as peculiaridades do autismo podem comprometer a entrada, a permanência e o progresso de alunos com esse diagnóstico na escola (PEETERS, 1998) e constatando a tendência na educação brasileira de aumento no número de matrículas de alunos com necessidades especiais em escolas regulares municipais da rede pública, torna-se fundamental conhecer e avaliar o impacto deste tipo de escolarização no desenvolvimento desses alunos.

Assim, o objetivo geral desse estudo consistiu em caracterizar o perfil dos alunos com autismo matriculados em escolas regulares do município de Belo Horizonte no ano de 2008, assim como caracterizar como é a escolarização desses alunos em classes comuns de escolas regulares, a partir da perspectiva de seus professores. Os objetivos específicos foram: traçar as características básicas dos alunos matriculados (ex. gênero, idade, presença ou ausência de fala); analisar como se dá a matrícula desses alunos (distribuição de alunos por séries/ciclos, correspondência entre a série/ciclo e a idade cronológica dos alunos); e levantar informações sobre suporte aos alunos e aos professores; dados sobre a frequência dos alunos; além de informações sobre a aprendizagem de conteúdos pedagógicos. 


\section{Método}

Participantes

O número total de alunos com autismo matriculados nas escolas regulares do município no ano de 2008, informado pelo Núcleo de Inclusão Escolar da Pessoa com Deficiência, órgão da Secretaria Municipal de Educação de Belo Horizonte, responsável pela educação de alunos com autismo em escolas regulares do município, foi de 68 alunos em 54 escolas. Desse total de escolas, foram selecionadas aleatoriamente para este estudo 33 escolas, o que representa $61 \%$ do total. Do total de escolas selecionadas, quatro foram excluídas do estudo pelos seguintes motivos: uma informou que o aluno indicado pelo Núcleo já tinha se formado, outra informou que o aluno indicado pelo Núcleo não tinha autismo, uma escola não foi encontrada e outra afirmou que o aluno indicado pelo Núcleo não frequentava a escola. Outras cinco escolas selecionadas se recusaram a participar da pesquisa $(9,2 \%$ do total). Uma escola selecionada informou que tinha mais um aluno com autismo matriculado, que não estava na lista do Núcleo de Inclusão (esse aluno foi incluído nesse estudo). Assim, o número provável de alunos com autismo matriculados em escolas regulares do município no ano de 2008 era de 65. Desse total de alunos, 33 professores participaram do estudo caracterizando 33 alunos com autismo, o que representa aproximadamente $50 \%$ do total de alunos com autismo matriculados.

\section{Situação e Materiais}

Os professores participantes responderam a um questionário semiestruturado com questões sobre: (1) dados do aluno (idade, diagnóstico e matricula); (2) tipos de suporte ao aluno e ao professor; (3) aspectos do aluno na escola (frequência, participação nas tarefas da turma e procedimentos de avaliação da escola); (4) aspectos sobre a comunicação e a aprendizagem do aluno; (5) comportamentos do aluno na escola. Foram utilizados protocolo em papel, caneta e gravador de áudio.

Os professores preencheram também a escala CARS - Childhood Autism Rating Scale (SCHOPLER; REICHLER; RENNER, 1988), instrumento que permite identificar pessoas com características comportamentais de autismo e distinguir entre autismo e atraso no desenvolvimento sem autismo. Ela é dividida em quinze áreas (relacionamento interpessoal; imitação; resposta emocional; expressão corporal; uso do objeto; adaptação a mudanças; uso do olhar; uso da audição; uso do paladar olfato e tato; medo e nervosismo; comunicação verbal; comunicação não-verbal; atividade; grau e consistência das respostas da inteligência; impressão geral) e em cada área há quatro grupos de sintomas com pontuação de 1 a 4 . Para o seu preenchimento deve-se escolher um dos quatro grupos de sintomas de cada área, podendo-se também escolher uma pontuação entre um e outro grupo de sintomas $(1,5 ; 2,5 ; 3,5)$. A soma dos pontos de cada área dá o resultado, que pode 
ser enquadrado em uma das três categorias: desenvolvimento normal (pontuação entre 15 e 29,5), autismo leve/moderado $(30$ a 36,5) e autismo grave (acima de 37 pontos). Pode ser preenchida por qualquer pessoa que tenha contato direto e frequente com a criança a ser analisada. A escala foi traduzida, adaptada e validada para o Brasil por Pereira, Riesgo e Wagner (2008). Para a aplicação da escala foram utilizados o formulário de pontuação da CARS e caneta.

\section{Procedimentos}

Tanto a forma de recrutamento dos participantes quanto os demais procedimentos empregados no estudo foram aprovados pelo Comitê de Ética em Pesquisa em Seres Humanos da Universidade Federal de São Carlos (Parecer número: 382/2008).

Inicialmente o Núcleo de Inclusão Escolar da Pessoa com Deficiência foi informado sobre esse estudo e concedeu a autorização para o início da pesquisa, além de fornecer as informações sobre todos os alunos com autismo matriculados nas escolas regulares do município no ano de 2008.

Identificados os alunos com autismo e suas respectivas escolas, realizouse contato telefônico com a direção de cada uma das instituições selecionadas para explicar os objetivos e convidar a instituição para participar do estudo. Obtida a anuência dos responsáveis pela escola, era agendada a visita à instituição para a assinatura do "Termo de Autorização e Ciência Institucional" pelo gestor. A seguir, a própria escola indicava o professor que poderia participar do estudo e este deveria atender ao critério de ter contato próximo e diário com o aluno com autismo. Estagiários e mediadores dos alunos com autismo não poderiam participar como informantes.

Aos professores selecionados eram apresentados os objetivos da pesquisa e feito o convite para a participação voluntária no estudo. Os anuentes assinavam o "Temo de Consentimento Livre e Esclarecido" e em seguida realizavam a entrevista semiestruturada e o preenchimento da escala CARS (SCHOPLER; REICHLER; RENNER, 1988).

As entrevistas com roteiro semiestruturado eram gravadas em áudio. $\mathrm{Na}$ sequência era pedido ao professor que preenchesse de forma independente a escala CARS, porém não era informado a ele que se tratava de uma escala para detecção de sinais de autismo (embora o participante soubesse previamente que se tratava de um estudo sobre autismo e, além disso, alguns itens da escala delatam a finalidade da mesma); era pedido a ele que lesse cuidadosamente cada grupo de sintomas e marcasse aqueles que mais se pareciam com o seu aluno. Caso o participante tivesse alguma dúvida durante o preenchimento da escala, poderia consultar imediatamente a pesquisadora. A realização da entrevista semiestruturada e o preenchimento da CARS tinham duração aproximada de quarenta minutos. Os dados foram coletados entre os meses de outubro e novembro de 2008. 


\section{RESUltados}

A Tabela 1 apresenta a lista dos alunos com autismo e suas principais características, conforme indicadas por seus professores. Os alunos foram agrupados por suas respectivas séries/ciclos e a idade, sexo, tempo de matrícula na escola, diagnóstico informado pela escola e a pontuação na CARS, foram explicitados.

Tabela 1 - Características Gerais dos Alunos com Autismo.

\begin{tabular}{|c|c|c|c|c|c|c|c|}
\hline & \multirow{2}{*}{ Aluno } & \multirow{2}{*}{ Idade } & \multirow{2}{*}{ Sexo } & \multirow{2}{*}{ Tempo na escola } & \multirow{2}{*}{ Diagnóstico Prévio ${ }^{4}$} & \multicolumn{2}{|c|}{ CARS } \\
\hline & & & & & & Pontuação & Resultado \\
\hline \multirow{7}{*}{ 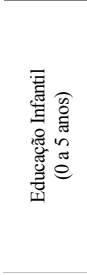 } & 3 & $5 \mathrm{a} 1 \mathrm{~m}$ & M & 1 ano & TID & 46 & grave \\
\hline & 5 & 3a $10 \mathrm{~m}$ & M & 1 ano & $\begin{array}{c}\text { Autismo, suspeita de Asperger ou } \\
\text { TOC }\end{array}$ & 20,5 & normal \\
\hline & 10 & $4 \mathrm{a} 2 \mathrm{~m}$ & M & 1 ano & Autismo & 38,5 & grave \\
\hline & 15 & $4 a$ & M & 1 ano & Autismo & 38,5 & grave \\
\hline & 20 & $3^{\mathrm{a}} 11 \mathrm{~m}$ & M & 1 ano & Autismo & 32 & leve/moderado \\
\hline & 28 & $4 \mathrm{a} 6 \mathrm{~m}$ & M & 2 ano & Autismo & 29,5 & normal \\
\hline & 33 & $4 \mathrm{a} 3 \mathrm{~m}$ & M & 1 ano & Autismo & 43 & grave \\
\hline \multirow{20}{*}{ 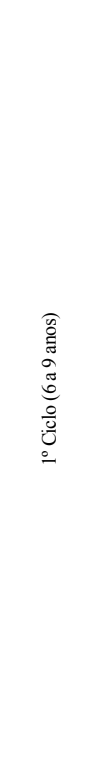 } & 1 & $9 \mathrm{a} 9 \mathrm{~m}$ & M & 2 anos & Autismo & 39,5 & grave \\
\hline & 2 & $11 \mathrm{a} 11 \mathrm{~m}$ & M & 3 anos & Autismo & 42 & grave \\
\hline & 4 & $10 \mathrm{a}$ & M & 1 ano e meio & Autismo e PC & 56 & grave \\
\hline & 8 & $11 \mathrm{a} 11 \mathrm{~m}$ & M & 2 anos & Autismo & 25 & normal \\
\hline & 9 & $11 \mathrm{a} 6 \mathrm{~m}$ & M & 1 ano & TID & 35,5 & leve/moderado \\
\hline & 11 & 6a $11 \mathrm{~m}$ & M & 1 ano & DM e distúrbio de comportamento & 26,5 & normal \\
\hline & 12 & $7 \mathrm{a} 8 \mathrm{~m}$ & M & 3 anos & TID & 38,5 & grave \\
\hline & 13 & $8 \mathrm{a} 11 \mathrm{~m}$ & M & 3 anos & Autismo e PC & 27 & normal \\
\hline & 14 & $8 \mathrm{a} 3 \mathrm{~m}$ & M & 1 ano & Autismo & 33,5 & leve/moderado \\
\hline & 16 & 7a $1 \mathrm{~m}$ & M & 1 ano & Autismo & 37 & grave \\
\hline & 17 & $8 \mathrm{a} 8 \mathrm{~m}$ & M & 2 anos e meio & TDAH & 27 & normal \\
\hline & 18 & $11 \mathrm{a}$ & $\mathrm{F}$ & 1 ano & TID & 33 & leve/moderado \\
\hline & 19 & 11 & M & 8 anos & $\begin{array}{l}\text { Atraso no desenvolvimento motor, } \\
\text { autismo e DM }\end{array}$ & 39,5 & grave \\
\hline & 22 & 9a $1 \mathrm{~m}$ & M & 3 anos & Autismo & 44 & grave \\
\hline & 23 & $7 \mathrm{a} 4 \mathrm{~m}$ & M & 4 anos & Autismo like & 51 & grave \\
\hline & 24 & $9 \mathrm{a} 4 \mathrm{~m}$ & M & 1 ano & Autismo & 27,5 & normal \\
\hline & 26 & $6 \mathrm{a} 11 \mathrm{~m}$ & M & 1 ano & TDAH & 35 & leve/moderado \\
\hline & 27 & $11 \mathrm{a} 6 \mathrm{~m}$ & M & 4 anos & $\begin{array}{l}\text { Transtorno de linguagem e TID não } \\
\text { especificado }\end{array}$ & 19 & normal \\
\hline & 29 & $7 \mathrm{a} 10 \mathrm{~m}$ & M & 2 anos & Transtorno de Asperger & 43,5 & grave \\
\hline & 32 & $6 \mathrm{a} 11 \mathrm{~m}$ & M & 1 ano & TID não especificado & 35,5 & leve/moderado \\
\hline \multirow{6}{*}{ 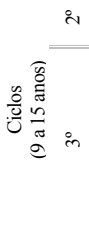 } & 6 & $12 \mathrm{a} 1 \mathrm{~m}$ & M & 6 anos & Autismo/Asperger & 44 & grave \\
\hline & 7 & $13 \mathrm{a} 2 \mathrm{~m}$ & $\mathrm{~F}$ & 2 anos & Autismo & 38 & grave \\
\hline & 21 & $15 \mathrm{a} 9 \mathrm{~m}$ & M & 3 anos & Autismo atípico & 34,5 & leve/moderado \\
\hline & 25 & 13a $11 \mathrm{~m}$ & M & 6 anos & Síndrome de Asperger & --- & --- M \\
\hline & 30 & $15 \mathrm{a} 10 \mathrm{~m}$ & M & 6 anos & Autismo & 19 & normal \\
\hline & 31 & $13 \mathrm{a} 2 \mathrm{~m}$ & $\mathrm{~F}$ & 3 anos & Autismo atípico & 31,5 & leve/moderado \\
\hline
\end{tabular}

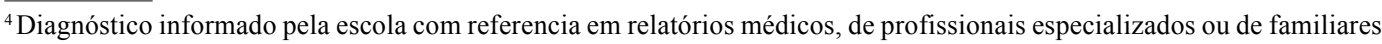
dos alunos. TID (Transtorno Invasivo do Desenvolvimento), TOC (Transtorno Obsessivo-Compulsivo), PC (Paralisia Cerebral), TDAH (Transtorno de Déficit de Atenção e Hiperatividade) e DM (Deficiência mental). 
Dos 33 alunos com autismo investigados, 91\% eram do sexo masculino. Entretanto, nove alunos do total apresentaram pontuação na CARS correspondente a desenvolvimento normal $(5,28,8,11,13,17,24,27,30)$, sugerindo que essas crianças podem não apresentar sintomas consistentes com a caracterização de autismo. Desses nove alunos, quatro tinham apenas o diagnóstico prévio de autismo $(28,8,24,30)$, e cinco tinham ou diagnóstico duplo de autismo associado a outros transtornos (5, 13 e 27) ou apenas o diagnóstico de outros transtornos (11 e 17). Portanto, $27 \%$ dos alunos notificados como tendo autismo não apresentavam sintomas claros de autismo segundo os critérios definidos pela CARS.

Dos alunos que apresentaram pontuação na CARS correspondentes a autismo, 8 deles (24\%) apresentaram autismo leve/moderado $(20,9,14,18,26,32$, $21,31)$ e 14 alunos $(45 \%)$ apresentaram indicadores de autismo grave $(3,10,15,33$, $1,2,4,12,16,19,22,23,29,6,7)$. Um professor (25) não preencheu a CARS.

Dos sete alunos com autismo leve/moderado, seis apresentavam diagnóstico prévio compatível com autismo $(20,9,14,18,32,21$ e 31) e apenas um deles não apresentava diagnóstico compatível com autismo (26 - Transtorno de déficit de atenção e hiperatividade).

Dos 15 alunos com autismo grave, 13 apresentavam diagnóstico prévio compatíveis com autismo $(3,10,15,33,1,2,12,16,22,23,29,6,7)$, sendo dois casos de Transtorno de Asperger $(29,6)$. Outros dois alunos tinham diagnóstico prévio de outros transtornos associados ao autismo (o 4 com paralisia cerebral, e o $19 \mathrm{com}$ atraso no desenvolvimento motor e deficiência mental).

A Tabela 2 apresenta a proporção de alunos com autismo em função dos diferentes procedimentos de identificação, considerando o diagnóstico prévio fornecido pelo sistema educacional (autismo com ou sem outros distúrbios associados) e a classificação da pontuação obtida através da CARS.

Tabela 2 - Distribuição dos Alunos em Relação ao Diagnóstico e à Pontuação na CARS.

\begin{tabular}{|c|c|c|c|c|c|}
\hline \multirow{2}{*}{ Diagnóstico } & \multicolumn{2}{|c|}{ Sim } & \multicolumn{2}{|c|}{ Não } & \multirow{2}{*}{$\begin{array}{c}\text { Total de } \\
\text { alunos }\end{array}$} \\
\hline & Número & Porcentagem & Número & Porcentagem & \\
\hline 1. Somente Autismo & 25 & $75,8 \%$ & 8 & $24,2 \%$ & 33 \\
\hline 2. Autismo e outros transtornos & 30 & $91 \%$ & 3 & $9 \%$ & 33 \\
\hline 3. Autismo e CARS & 20 & $62,5 \%$ & 12 & 37,5 & 32 \\
\hline 4. Autismo, outros transtornos e CARS & 25 & $78,1 \%$ & 7 & $21,9 \%$ & 32 \\
\hline 5. CARS & 23 & $71,9 \%$ & 9 & $28,1 \%$ & 32 \\
\hline
\end{tabular}

A proporção de alunos com diagnóstico prévio de autismo (incluindo Autismo, Transtorno invasivo do desenvolvimento, Autismo like, Asperger, Transtorno invasivo não especificado e Autismo atípico), sem outros transtornos associados, foi de $75,8 \%$ contra $24,2 \%$ de alunos sem diagnóstico prévio exclusivo de autismo. Porém, se considerarmos os alunos com diagnóstico prévio de autismo somado aos alunos com diagnóstico de autismo e outros diagnósticos associados, 
cerca de $91 \%$ dos alunos investigados teria autismo enquanto 9\% não teria autismo. Considerando apenas os alunos que tiveram somente o diagnóstico prévio de autismo e a pontuação compatível com autismo na CARS, $62,5 \%$ dos alunos teria autismo enquanto $37,5 \%$ não teria autismo. Mas, se somarmos os alunos com diagnóstico de autismo, com aqueles com diagnóstico de autismo e outros transtornos, e que obtiveram pontuação relativa a autismo na CARS, cerca de 78,1\% dos alunos teria autismo, enquanto $21,9 \%$ não teria autismo. Por outro lado, se forem considerados apenas os alunos que obtiveram pontuação relativa a autismo na CARS, independente do diagnóstico prévio, constatamos que cerca de $71,9 \%$ dos alunos teria autismo enquanto $28,1 \%$ não teria autismo.

Prosseguindo a análise dos dados optou-se por considerar nesse estudo apenas os alunos que apresentaram sintomas de autismo leve/moderado e autismo grave pela CARS, independente do diagnóstico prévio identificado nas escolas. A amostra final ficou composta por cinco alunos da Educação Infantil (3, 10, 15, 20 e $33)$, e 18 do ensino fundamental, dos quais 14 estavam no $1^{\circ}$ ciclo $(1,2,4,9,12,14$, $16,18,19,22,23,26,29$ e 32$)$ e quatro no $2^{\circ}$ e $3^{\circ}$ ciclos $(6,7,21$ e 31$)$. Todas as entrevistas semiestruturadas realizadas com os professores desses alunos foram gravadas em áudio, dois auditores independentes e ingênuos em relação ao propósito da pesquisa registraram $30 \%$ das entrevistas e a porcentagem de concordância foi de $100 \%$. Em relação à CARS, como o preenchimento era realizado pelo próprio professor de forma independente, a pesquisadora apenas contabilizou a pontuação total.

Quanto ao suporte à escolarização dos alunos, foram identificados três tipos de apoios: (1) auxiliar de vida escolar (estagiário que acompanhava a criança dentro da escola no período escolar), (2) acompanhamento de profissionais especializados extraescolar e (3) escolarização especializada, ofertada no contra turno à frequência da classe comum da escola regular. Destaca-se que nenhuma das escolas participantes tinha classes especiais ou salas de recurso. A Figura 1 apresenta a porcentagem de alunos com cada tipo de suporte na educação infantil, $1^{\mathrm{o}}$ ciclo, $2^{\circ}$ e $3^{\circ}$ ciclos.

Cerca de $40 \%$ dos alunos da educação infantil, $90 \%$ do $1^{\circ}$ ciclo e $40 \%$ do $2^{\circ}$ e $3^{\circ}$ ciclos possuíam um auxiliar de vida escolar. Os auxiliares de vida escolar, em todos os casos, eram estudantes (Figura 2), que estavam cursando o ensino médio (76,5\%) ou ensino superior (23,5\%). Aproximadamente $60 \%$ dos alunos da educação infantil, $70 \%$ do $1^{\circ}$ ciclo e $100 \%$ do $2^{\circ}$ e $3^{\circ}$ ciclo eram acompanhados por profissionais especializados extraescolar. Apenas um aluno do $1^{\circ}$ ciclo frequentava escola especial, além da escola regular. 


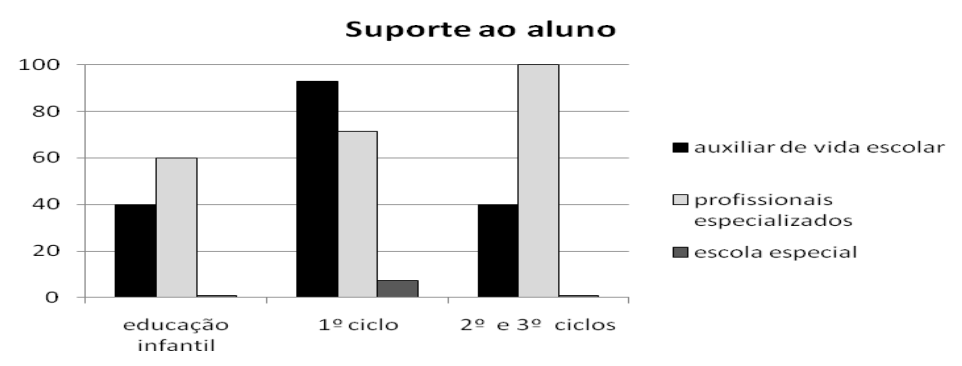

Figura 1 - Porcentagem de alunos com suporte na educação infantil, $1^{\circ}$ ciclo, $2^{\circ}$ e $3^{\circ}$ ciclos.

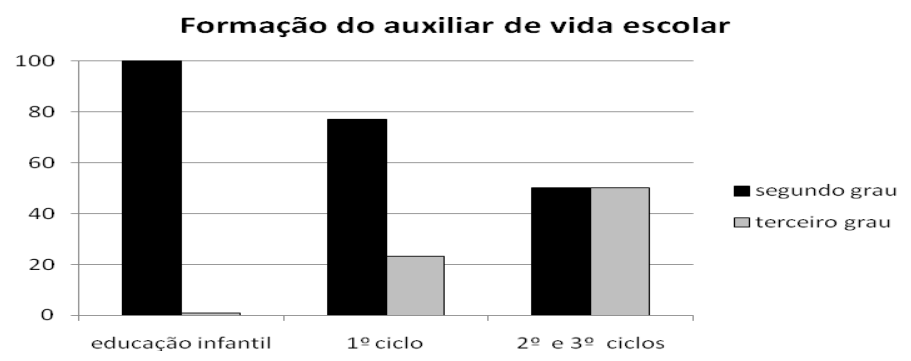

Figura 2 - Distribuição porcentual dos auxiliares de vida escolar que cursavam o segundo e o terceiro grau, por etapa de ensino.

Sobre o suporte aos professores, 54\% afirmaram recebê-lo do município (Núcleo de Inclusão ou Equipe de Inclusão da Regional) e nenhum outro tipo de suporte foi citado pelos professores. Em relação à frequência desse suporte, a maioria dos professores afirmou tratar-se de um apoio ocasional. A Figura 3 apresenta à esquerda, a porcentagem total de professores, por etapa escolar, que declararam ter suporte e à direita, a distribuição da frequência desse suporte: ocasional (de duas a cinco vezes no ano letivo) ou sistemático (semanal ou quinzenal). 

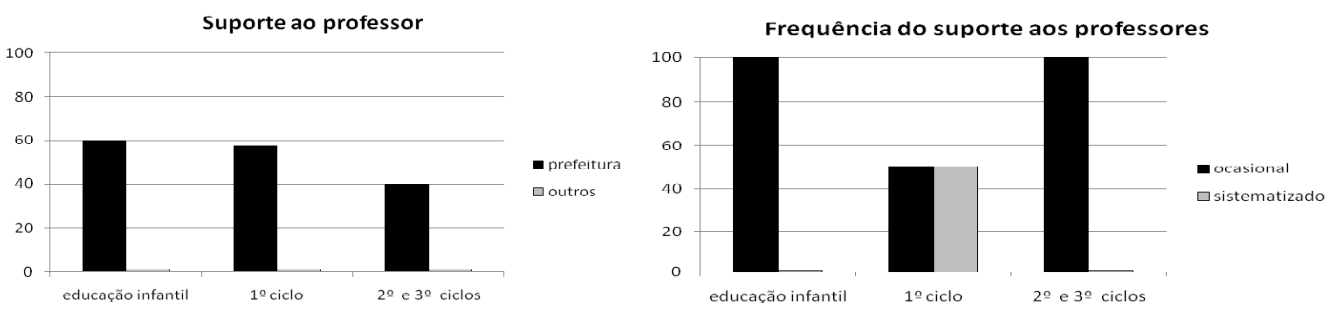

Figura 3 - Porcentagem total de professores, por etapa escolar, que declararam ter suporte na escolarização dos alunos com autismo (esquerda). Distribuição da frequência do suporte oferecido pelo município (direita).

Em relação à frequência dos alunos, os professores indicaram que a maioria deles apresentava poucas faltas (Figura 4). Sobre a relação entre a idade dos alunos e a série/ciclo em que estavam matriculados, observa-se que a correspondência entre os dois ocorre em $100 \%$ dos casos na educação infantil. No $1^{\circ}, 2^{\circ}$ e $3^{\circ}$ ciclos entre $50 \%$ e $60 \%$ dos alunos estavam matriculados em etapas que não correspondiam ao esperado para a idade cronológica (Figura 4).
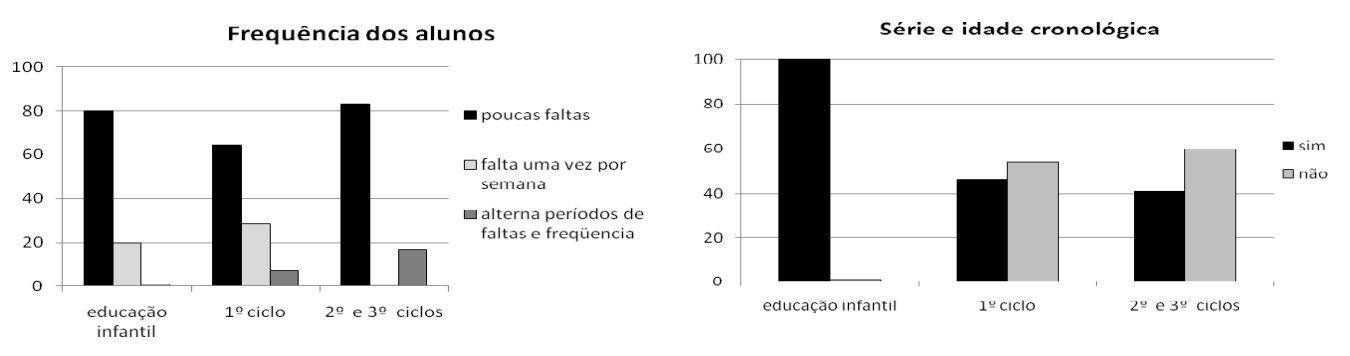

Figura 4 - Distribuição porcentual da frequência dos alunos por etapa educacional (esquerda). Distribuição porcentual dos alunos com autismo que estão matriculados em etapa escolar correspondente à idade cronológica (direita).

Em relação à participação dos alunos com autismo nas atividades escolares, observa-se variação nas diferentes etapas (Figura 5). No que se refere à permanência em sala de aula, $80 \%$ dos alunos da educação infantil, $40 \%$ do $1^{\circ}$ ciclo e $60 \%$ do $2^{\circ}$ e $3^{\circ}$ ciclos permaneciam em sala de aula durante todo o tempo da jornada escolar; o restante dos alunos não permanecia em sala de aula ou permanecia "às vezes". Esses dados sugerem que na educação infantil pode ser mais fácil manter alunos com autismo em sala de aula comum, contrariamente ao $1^{\circ}$ ciclo, no qual a 
porcentagem de alunos fora da sala de aula é superior a porcentagem dos que nela permanecem o tempo todo e durante todos os dias da semana.

A participação dos alunos com autismo nas tarefas de sua turma, no geral, é considerada baixa, sendo que no $1^{\circ}$ ciclo, praticamente nenhum aluno com autismo participava "sempre" das atividades de seu grupo de colegas. Sobre a realização de atividades idênticas às dos colegas ou a realização de atividades diferenciadas, observa-se que na educação infantil, a porcentagem de alunos que realizava tarefas idênticas e diferenciadas é a mesma. No $1^{\circ}$ ciclo, a porcentagem de alunos que realizava atividades diferenciadas é maior do que a porcentagem daqueles que realizavam atividades idênticas; observa-se também nesse ciclo que a porcentagem de alunos que "nunca" realizavam atividades idênticas às dos colegas é de $60 \%$. Nos $2^{\circ}$ e $3^{\circ}$ ciclos, a situação se inverte e a porcentagem de alunos que realizavam atividades diferenciadas é menor do que a porcentagem dos alunos que realizavam atividades idênticas às dos colegas. De forma geral, observa-se que a realização frequente de atividades, sejam elas idênticas ou diferenciadas, em todas as etapas escolares, é baixa, variando de 10 a $50 \%$ dos alunos.

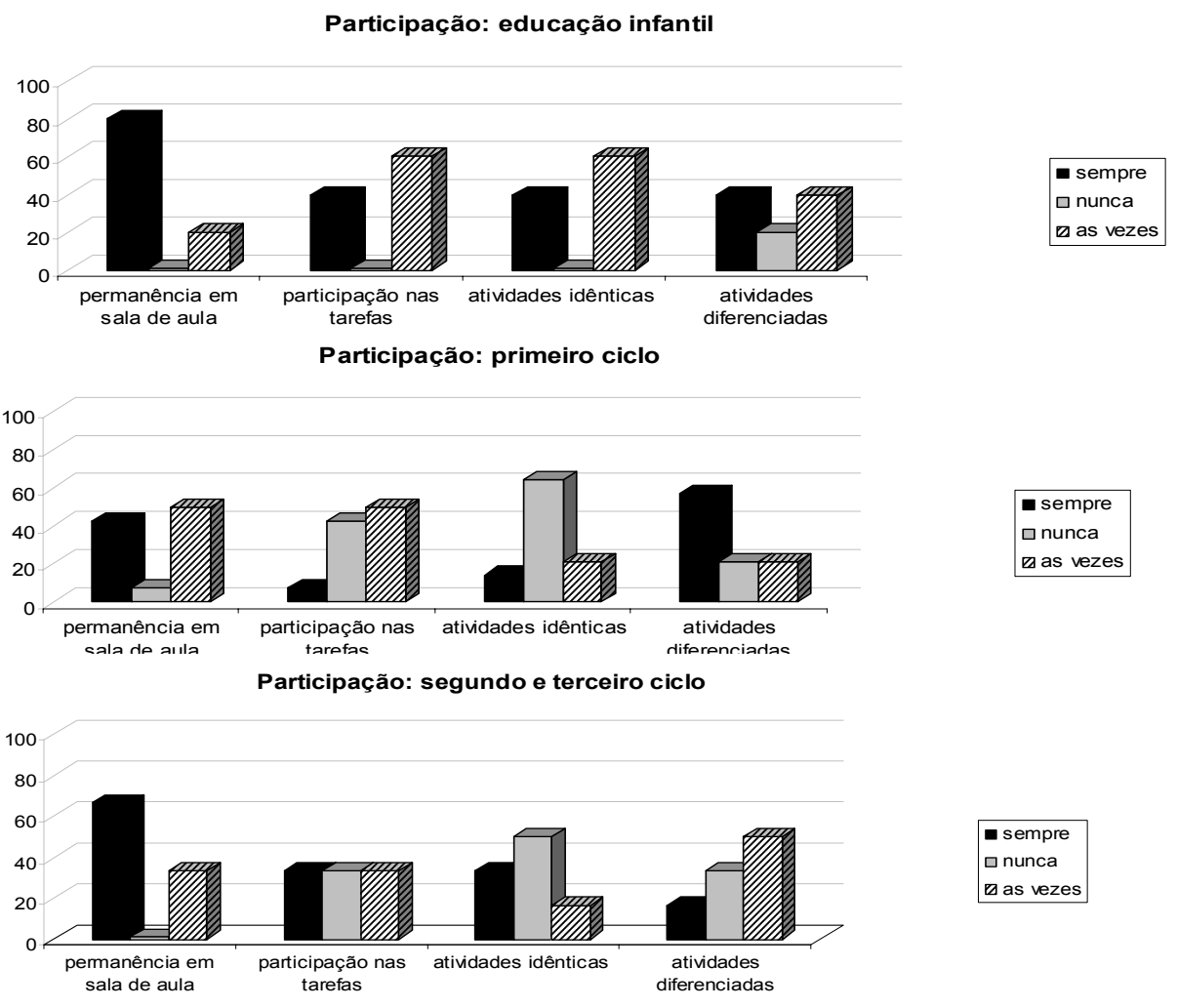

Figura 5 - Distribuição porcentual da participação dos alunos com autismo na educação infantil, primeiro ciclo, segundo e terceiro ciclos em: permanência em sala de aula, participação nas tarefas da turma, realização de atividades idênticas às dos colegas e realização de atividades diferenciadas dos colegas. 
Sobre a maneira como os professores avaliavam seus alunos com autismo (Figura 6), percebe-se também variação nas etapas de ensino: a avaliação era predominantemente idêntica à dos colegas na educação infantil, porém o quadro se inverte no $1^{\circ}$ ciclo, tornando-se predominantemente diferenciada. Já no $2^{\circ}$ e $3^{\circ}$ ciclos, observa-se uma porcentagem igualitária na avaliação: 50\% dos professores relataram avaliar seus alunos com autismo de maneira diferenciada enquanto os outros $50 \%$ afirmaram avaliar de forma igual.

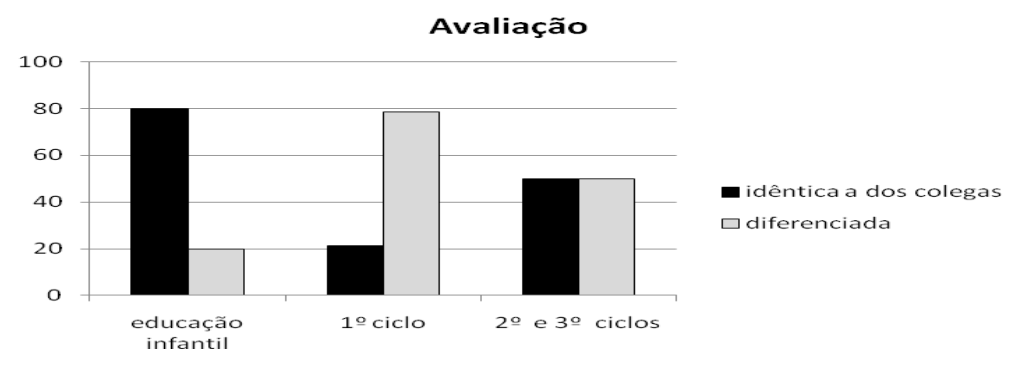

Figura 6: Distribuição porcentual da maneira como os professores avaliavam seus alunos com autismo, por etapa escolar.

$\mathrm{Na}$ área de comunicação e aprendizagem, observa-se que aproximadamente $40 \%$ dos alunos da educação infantil falavam e essa porcentagem sobe para $60 \%$ no $1^{\circ}$ ciclo e $100 \%$ no $2^{\circ}$ e $3^{\circ}$ ciclos, indicando que a proporção de alunos não falantes é maior na educação infantil.

Em relação à aprendizagem de habilidades pedagógicas básicas, percebese que a porcentagem de alunos que sabiam ler, escrever, fazer contas e que acompanhavam os conteúdos pedagógicos ficou abaixo de $10 \%$ no $1^{\circ}$ ciclo e abaixo de $60 \%$ no $2^{\circ}$ e $3^{\circ}$ ciclos (Figura 7 ). No geral, observa-se que em torno de $90 \%$ dos alunos com autismo não acompanham os conteúdos pedagógicos desenvolvidos pelas escolas. A aprendizagem de conteúdos pedagógicos não foi avaliada na educação infantil em função das características dessa etapa de escolarização que não exige esse tipo de conteúdo. 


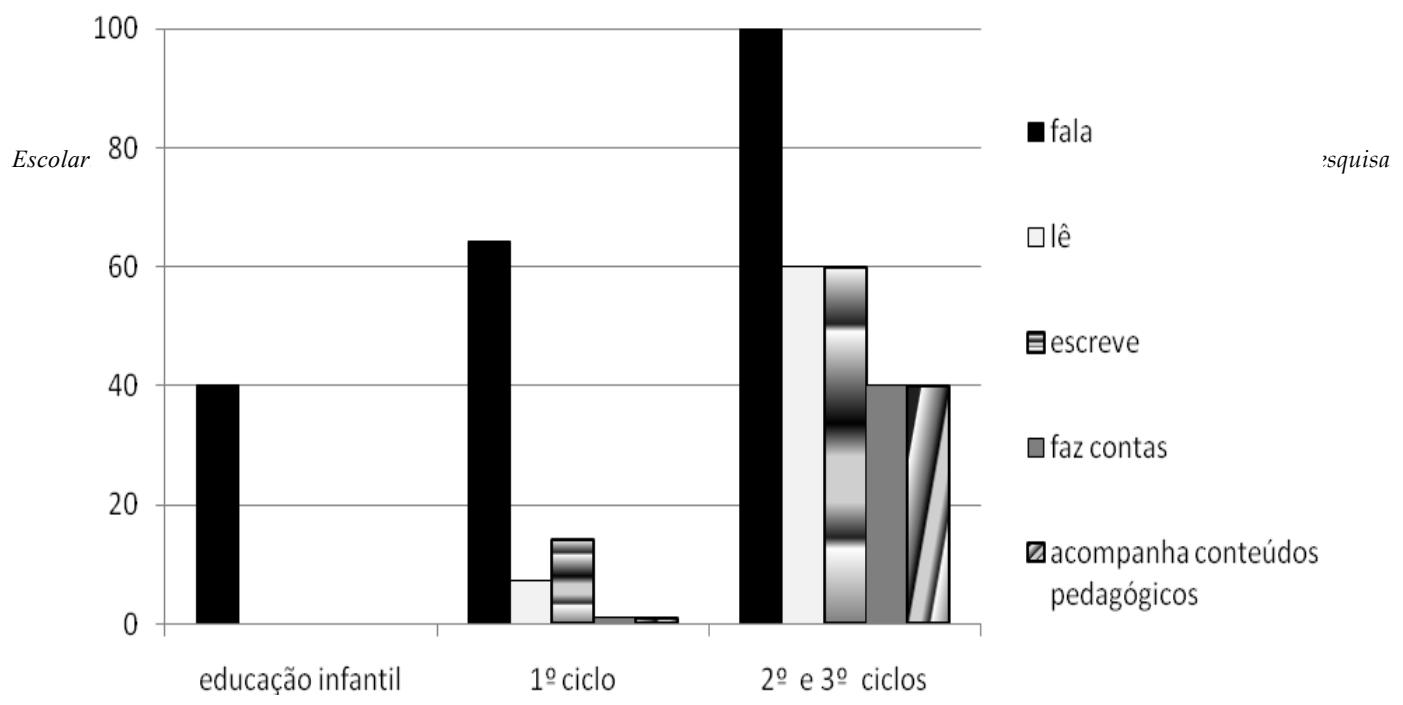

Figura 7: Distribuição porcentual dos alunos com autismo na educação infantil, $1^{\circ}$ ciclo, $2^{\circ}$ e $3^{\circ}$ ciclos em: presença de fala, leitura, escrita, realização de contas e acompanhamento de conteúdos pedagógicos.

Sobre os comportamentos dos alunos com autismo, observa-se semelhanças nas etapas educacionais (Figura 8). A maioria dos alunos interagia com seus colegas "sempre" ou "às vezes". A frequência da emissão de comportamentos dos alunos que o professor julgava serem difíceis de lidar ocorria "às vezes" entre 60 e $70 \%$ em todas as etapas. Sobre as dificuldades ou dúvidas do professor (escola) em relação à maneira de lidar com seu aluno com autismo, 40\% dos professores afirmaram que isso "nunca" ocorre. Percebe-se também uma alta porcentagem na participação das famílias dos alunos com autismo no processo de escolarização de seus filhos. 


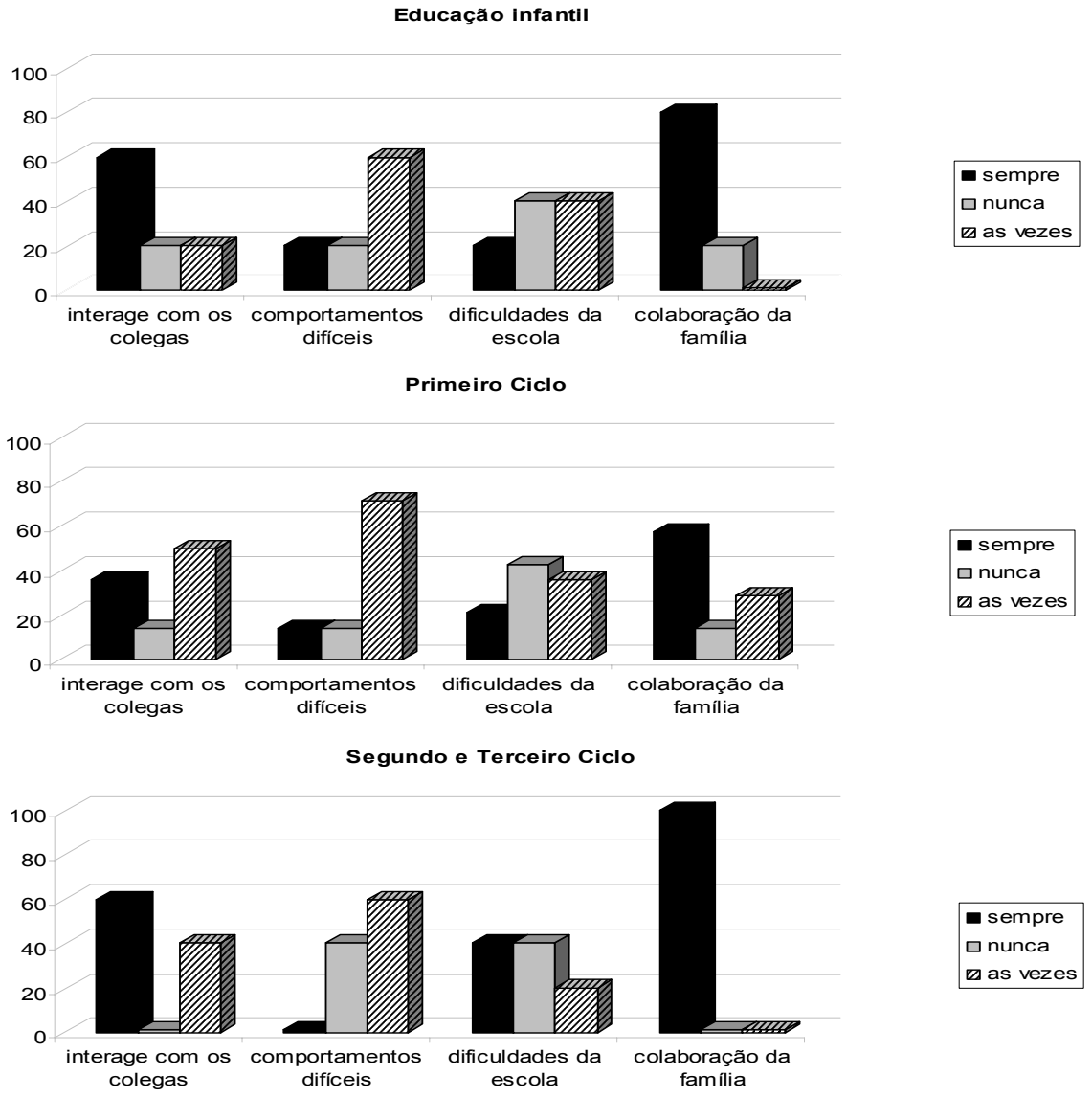

Figura 8: Distribuição porcentual dos alunos com autismo na educação infantil, $1^{\circ}$ ciclo, $2^{\circ}$ e $3^{\circ}$ ciclos em: interação com os colegas, frequência da emissão de comportamentos do aluno com autismo que o professor julga serem difíceis de lidar, frequência de dúvidas ou dificuldades da escola na maneira de lidar com o aluno com autismo e colaboração das famílias dos alunos com autismo na escolarização de seus filhos.

\section{Discussão e CONCLUSÕES}

O objetivo desse estudo foi descrever a escolarização de alunos com autismo matriculados em escolas regulares da rede municipal de ensino de Belo Horizonte no ano de 2008, a partir da perspectiva de seus professores.

Os primeiros pontos a serem observados referem-se ao diagnóstico prévio dos alunos; a seleção dos alunos com autismo realizada pelo Núcleo de Inclusão do município e; a relação entre o diagnóstico de autismo e a pontuação na CARS. 
Em relação ao diagnóstico prévio dos alunos, observou-se uma variedade de nomes apontados nos relatórios de médicos, de profissionais especializados ou de familiares dos alunos (TID; autismo; autismo like; TID não especificado; autismo atípico). Essa variedade reflete a multiplicidade de termos utilizados para nomear os transtornos do espectro autístico e também a diversidade no perfil das pessoas com autismo, descritas na literatura especializada (WING, 1996)

Sobre o levantamento dos alunos com autismo realizado pelo Núcleo de Inclusão do município, observa-se imprecisão nos números, já que três alunos apontados com tendo autismo não tinham o diagnóstico prévio de autismo $(11,17$ e 26) e dois deles nem tinham sintomas consistentes de autismo com referência na CARS. Esses números indicam que algumas variáveis podem estar interferindo na identificação dos alunos com autismo pelo Núcleo de Inclusão, como a falta de clareza de pais, médicos e profissionais especializados sobre o diagnóstico desses alunos, dada a complexidade da definição do diagnóstico de autismo (ASSUMPÇÃO, 2005) ou mesmo a dificuldade das escolas em detectar alunos com autismo e distingui-los de alunos com outros transtornos do desenvolvimento.

Outro ponto a ser observado em relação ao diagnóstico é o fato de praticamente um terço dos alunos investigados, tendo diagnóstico prévio ou não de autismo, não terem apresentado sintomas consistentes de autismo com referência na CARS, preenchida por seus professores. Essa escala é um instrumento de fácil utilização (nenhum professor teve dificuldades em respondê-la), que pode ser preenchida por qualquer pessoa e não requer conhecimento prévio sobre autismo, apenas conhecimento prévio sobre os comportamentos típicos da criança a ser analisada. A CARS sozinha não é suficiente para se fazer o diagnóstico de autismo, porém pode indicar com segurança se uma criança apresenta um conjunto de sintomas característicos de autismo ou não. $O$ fato de um terço dos alunos não terem obtido pontos referentes a autismo na CARS pode indicar falta clareza sobre o diagnóstico desses alunos, assim como imprecisão na avaliação dos professores sobre o comportamento de seus alunos.

Em relação aos suportes dos alunos com autismo, destaca-se a alta porcentagem de auxiliares de vida escolar, especialmente no $1^{\circ}$ ciclo, pois $90 \%$ dos alunos estavam com este tipo de apoio. O principal benefício disso pode estar na alta frequência dos alunos e no baixo número de faltas, já que tendo um estagiário com dedicação integral ao aluno com autismo, provavelmente os pais tendem a ficar mais tranquilos em deixar seus filhos na escola. Por outro lado, com um auxiliar de vida escolar, as escolas e os professores têm a possibilidade de flexibilizar a participação de seus alunos com autismo nas tarefas de sua turma, e em situações em que o aluno com autismo apresente dificuldades em realizar as mesmas tarefas de sua turma dentro de sala de aula, o estagiário poderia auxiliar o professor na execução de uma tarefa alternativa, fora da sala de aula. Entretanto, um problema que pode comprometer a atuação dos auxiliares de vida escolar é o baixo grau de instrução dos estagiários, pois cerca de $80 \%$ deles são estudantes de segundo grau, 
e leigos, por não terem uma formação específica para a função que exercem. Nesse caso, para que esses profissionais de apoio sejam capazes de mediar as relações da criança no meio escolar, auxiliar na interação social, autonomia e aprendizagem, é necessário que haja capacitação e supervisão constantes, senão corre-se o risco do auxiliar torna-se apenas um cuidador, perdendo as funções educacionais que ele deveria ter para que o aluno com autismo participe ativamente do processo escolar.

Em relação ao suporte aos professores, entre $40 \%$ e $60 \%$ deles afirmaram receber apoio do município no formato de orientação, porém, na maioria dos casos, trata-se de um suporte ocasional, que devido ao grande espaço de tempo entre uma orientação e outra, pode ser pouco efetivo e pouco motivador.

Sobre a relação entre a série/ciclo e a idade cronológica dos alunos, está só corresponde em $100 \%$ dos casos na educação infantil; no $1^{\circ}, 2^{\circ}$ e $3^{\circ}$ ciclos, em torno de $40 \%$ dos alunos com autismo estão em etapas que não correspondem à idade cronológica esperada. Provavelmente essa disparidade ocorre em função dos conteúdos pedagógicos; na educação infantil não há a necessidade da aprendizagem de conteúdos específicos como a leitura, a escrita e a matemática e não há uma avaliação quantitativa da aprendizagem, assim os objetivos e os critérios educacionais são mais flexíveis. Nas etapas dos ciclos há a necessidade de aprendizagem de conteúdos pedagógicos específicos, avaliações quantitativas e caso o aluno não atinja os objetivos para aquela etapa pode ser "retido", ou seja, pode ficar mais de um ano em uma mesma etapa escolar. No caso dos alunos com autismo, como a maioria deles não acompanha os conteúdos pedagógicos, provavelmente devem ser frequentemente retidos, o que acaba causando a distorção entre a série/ciclo e a idade cronológica. Fenômeno semelhante pode ser observado em relação à avaliação: na educação infantil ela é idêntica à dos colegas em $100 \%$ dos casos, enquanto que no $1^{\circ}$ ciclo ela é predominantemente diferente e no $2^{\circ}$ e $3^{\circ}$ ciclos ela é idêntica em $50 \%$ dos casos.

Em relação à permanência em sala de aula, a maioria dos alunos com autismo da educação infantil permanece em sala de aula "sempre", o que sugere que talvez seja mais fácil manter esses alunos em sala nesse período educacional, provavelmente em função dos conteúdos trabalhados na educação infantil que são mais flexíveis e interessantes para as crianças. Além disso, nessa idade, pode ser mais fácil lidar com problemas de interação social, comunicação e comportamentos que uma criança com autismo possa apresentar. Nas outras etapas escolares, cerca de $30 \%$ dos alunos do $2^{\circ}$ e $3^{\circ}$ ciclos e praticamente a metade dos alunos do $1^{\circ}$ ciclo permaneciam em sala de aula "às vezes" e a repercussão disso pode estar na baixa aprendizagem de conteúdos pedagógicos e na pouca participação dos alunos com autismo nas atividades escolares. Por mais que a literatura especializada tenha relatado que pessoas com autismo apresentam dificuldades em aprender pelos métodos de ensino tradicionais (PEETERS, 1998), a baixa permanência em sala de aula diminui ainda mais as chances de aprendizado de conteúdos pedagógicos. 
Nenhum tipo de adequação da metodologia de ensino e dos conteúdos pedagógicos foi relatada pelos professores, além disso, não foi relatado também o uso de recursos de comunicação alternativa por alunos não falantes. A porcentagem de alunos não falantes na educação infantil é alta, assim como a porcentagem de alunos do $1^{\circ}$ ciclo que não aprenderam habilidades pedagógicas básicas. Esses alunos poderiam ser beneficiados por estratégias de ensino diferenciadas e pelo uso de recursos de comunicação alternativa, que vêm se mostrando eficazes para pessoas com autismo (BONDY; FROST, 1994). No caso da educação infantil, programas de intervenção precoce não foram relatados, embora a literatura apresente dados consistentes dos efeitos desse tipo de trabalho no desenvolvimento de crianças com autismo (AIELLO, 2002).

Em relação aos comportamentos dos alunos com autismo, observa- se semelhanças nas etapas escolares; a maioria deles interage com seus colegas "sempre" ou "às vezes" e entre $60 \%$ e $70 \%$ dos alunos apresentam comportamentos difíceis de lidar "às vezes". Apesar da baixa aprendizagem, pouca participação dos alunos com autismo nas tarefas de sua turma e a presença de comportamentos difíceis de lidar, cerca de $40 \%$ dos professores afirmou "nunca" ter dúvidas ou dificuldades em lidar com seus alunos com autismo. Possivelmente a presença do auxiliar de vida escolar na classe desonera o professor do ensino comum da tarefa de lidar com alunos que não falam, que não participam das atividades, que não aprendem e que apresentem comportamentos difíceis de lidar.

De maneira mais geral observa-se que as estratégias utilizadas pela prefeitura parecem favorecer a frequência dos alunos com autismo nas escolas regulares, o que pode ser considerado um avanço. Porém os dados sugerem pouca participação desses alunos nas atividades da escola, baixa interação com os colegas e pouca aprendizagem de conteúdos pedagógicos. O principal apoio oferecido pelo sistema municipal é a presença dos estagiários funcionando como auxiliares de vida escolar, mas pelo visto, os benefícios maiores deste tipo de suporte se voltam mais para os professores e para o sistema educacional do que para os alunos com autismo, pois com a oferta de suporte de baixo custo, em comparação ao quanto seria se houvesse a contratação de profissionais especializados, as demandas que surgem com a presença do aluno com autismo na sala de aula podem estar amenizadas com a contratação de leigos.

O apoio de auxiliares leigos na escola para crianças com necessidades educacionais especiais pode ser um recurso valioso, se o plano educacional individualizado do aluno pressupõe que isto seja necessário. Entretanto, não se trata de um recurso que deve ser utilizado indiscriminadamente, e muito menos para substituir a oferta de apoios de profissionais especializados e qualificados para responder as necessidades diferenciadas destas crianças, como parece ser o caso. Crianças com necessidades educacionais especiais precisam ter seu direito a educação assegurado, e de nada adianta assegurar a presença delas na escola se o direito à educação continuar sendo mascarado pelo assistencialismo e pela tutela. 
Assim, no momento em que este sistema educacional estudado já conseguiu assegurar o acesso e a permanência dos alunos com autismo nas classes comuns de escolas regulares, o próximo passo deveria ser o de oferecer às escolas condições para que possam desenvolver ao máximo o potencial desses alunos.

Apesar de o professor ser uma boa fonte de informação sobre seus alunos, seria interessante a realização de outros estudos de caracterização que utilizassem dados de observação direta e análise documental, a fim de diminuir possíveis vieses no estudo decorrente de variáveis do professor, como por exemplo, as características da relação do professor com o aluno a ser investigado; alguns professores são mais afetuosos e tendem a "proteger" o aluno não apontando as dificuldades que eles realmente apresentam, ou o inverso; professores tendem a achar que o aluno apresenta mais dificuldades do que realmente acontece.

Seria interessante também a realização de estudos posteriores comparando as características de alunos com autismo nas escolas regulares com as características de seus colegas de desenvolvimento típico (pares de idade); estudos longitudinais que pudessem acompanhar a permanência, progresso e desenvolvimento desses alunos com autismo nas escolas regulares do município ao longo dos anos; pesquisas que avaliassem os efeitos de intervenções específicas para o autismo no desenvolvimento dos alunos do município (ex. intervenção precoce e comunicação alternativa); estudos que comparassem a escolarização de alunos com autismo e de alunos com outras deficiências e; trabalhos comparando a escolarização de alunos com autismo em diferentes municípios, e em escolas públicas e privadas.

\section{REFERÊNCIAS}

AIELLO, A.L.R. Identificação precoce de sinais de autismo. In: GUILHARDI, H.J. et al. Sobre comportamento e cognição: contribuições para construção da Teoria do Comportamento. Santo André: ESETec Editores Associados, p. 13-29, 2002.

ALVES, M.D. As representações sociais dos professores acerca da inclusão de alunos com distúrbios globais do desenvolvimento. 2005. Dissertação (Mestrado em Educação) - Universidade Federal de Santa Maria, Rio Grande do Sul, 2005.

ASSOCIAÇÃO AMERICANA DE PSIQUIATRIA. Manual diagnóstico e estatístico de transtornos mentais: texto revisado. 4. ed. Porto Alegre: Artes Médicas, 2002.

ASSUMPÇÃO, F. Diagnóstico diferencial dos transtornos abrangentes de desenvolvimento. In: CAMARGOS, J.R.W. Transtornos invasivos do desenvolvimento: $3^{\circ}$ milênio. Brasília: CORDE, p. 16-19, 2005.

BAIRD et al. Prevalence of disorders of the autism spectrum in a population cohort of children in South Thames: the Special Needs and Autism Project (SNAP). Lancet, 368, p. 210-215, 2006.

BELO HORIZONTE. Política educacional da rede municipal de educação de Belo Horizonte: inclusão escolar de pessoas com deficiências. Belo Horizonte, Brasil, 2007. 
BELO HORIZONTE. Inclusão de Pessoas com Deficiências. Secretaria Municipal de Educação, Belo Horizonte, 2008. Disponível em: <http://portal1.pbh.gov.br/pbh/ index.html?id_conteudo=12791\&id_nivel1 $=-1 \&$ ver_servico $=$ N\#inclusao $>$. Acesso em: mar. 2008.

BLAXILL, M.F. What's going on? The question of time trends in autism. Public Health Reports, p. 536-551, 2004.

BONDY, A.S.; FROST, L.A. The picture exchange communication system training manual. Cherry Hill: Pyramid Educational Consultants, 1994.

BRAGA, M.C.B. A Interação professor aluno em classe inclusiva: um estudo exploratório com criança autista. Dissertação (Mestrado em Educação) - Universidade Estadual Paulista, São Paulo, 2002.

BRASIL. Constituição da República Federativa do Brasil, Brasília, 1988.

. Leis de Diretrizes e Bases da Educação. Ministério da Educação, Brasília, 1996.

. Dados da Educação Especial no Brasil. Ministério da Educação, Brasília, 2007.

Disponível em: <http:// portal.mec.gov.br/seesp/arquivos/pdf/brasil.pdf.>. Acesso em: março de 2008.

. Política nacional de educação especial na perspective da educação inclusiva. Secretaria de Educação Especial, Ministério da Educação, Brasília, 2008.

FILIPEK, P.A. et al. The screening and diagnosis of autistic spectrum disorders. Journal of Autism and Developmental Disorders, 29, p. 439-484, 1999.

KERN, C. Um processo considerado bem-sucedido de inclusão escolar e a síndrome do autismo: uma história com muitas vidas. Dissertação (Mestrado em Educação) - Universidade Federal de Santa Catarina, Santa Catarina, 2005.

KLIN, A. Autismo e Síndrome de Asperger: uma visão geral. Revista Brasileira de Psiquiatria, v.28, p.3-11, 2006.

LAGO, M. Autismo na escola: ação e reflexão do professor. Dissertação (Mestrado em Educação) - Universidade Federal do Rio Grande do Sul, Rio Grande do Sul, 2007.

LIRA, S.M. Escolarização de alunos com Transtorno Autista: histórias de sala de aula. Dissertação (Mestrado em Educação) - Universidade do Estado do Rio de Janeiro, Rio de Janeiro, 2004.

MANTRY et al. The prevalence and incidence of mental ill-health in adults with Down syndrome. Journal of Intellectual Disability Research, v.52, p.141-155, 2008.

MARTINS, M.R.R. Inclusão de alunos autistas no ensino regular: concepções e práticas pedagógicas de professores regentes. Dissertação (Mestrado em Psicologia) - Universidade Católica de Brasília, Brasília, 2007.

MELO, S.C. Autismo e educação: a dialética da inclusão. Dissertação (Mestrado em Educação) - Universidade Estadual do Rio de Janeiro, Rio de Janeiro, 2004.

PEETERS, T. Autismo: entendimento teórico e intervenção educacional. Rio de Janeiro: Cultura Médica, 1998.

PEREIRA, A.M.; RIESGO, R.; WAGNER M.B. Autismo infantil: tradução e validação da Childhood Autism Rating Scale. Jornal de Pediatria, v. 84, p. 487-494, 2008.

RUBLESCKI, A.F. A caminho da escola... um estudo sobre a educação integrada de crianças com autismo e psicose infantil. Dissertação (Mestrado em Educação) - Universidade Federal do Rio Grande do Sul, Rio Grande do Sul, 2004. 
GOMES, C.G.S.; MENDES, E.G.

SCHOPLER, E.; REICHLER, J. R.; RENNER, C. CARS-The Childhood Autism Rating Scale. Los Angeles: Westerm Pychological Services, 1988.

SERRA, D.C.G. A inclusão de uma criança com autismo na escola regular: desafios e processos. Dissertação (Mestrado em Educação) - Universidade do Estado do Rio de Janeiro, Rio de Janeiro, 2004.

. Entre a esperança e o limite: um estudo sobre a inclusão de alunos com autismo em classes regulares. Tese (Doutorado em Psicologia Clínica) - Pontifícia Universidade Católica do Rio de Janeiro, Rio de Janeiro, 2008.

WING, L. Que é autismo? In: ELLIS, K. Autismo. Rio de Janeiro: Revinter, p. 1-20, 1996.

Recebido em: $22 / 02 / 2010$

Reformulado em: 05/08/2010

Aprovado em: 04/11/2010 